\title{
Por una ética situacional en Educación Social
}

\section{A situational ethics to Social Education A ética situacional de Educação Social}

\author{
Margarita Campillo Díaz \\ Juan Sáez Carreras \\ UNIVERSIDAD DE MURCIA
}

\section{Resumen}

La mayoría de los planteamientos éticos relacionados con las actividades de las profesiones, entre los que se encuentra la Educación Social, se han realizado desde las llamadas éticas profesionales, normalmente pensadas desde enfoques funcionalistas e idealizantes y con frecuencia asociadas a un catálogo de principios e imperativos formulados a modo de guía u orientación de lo que deben hacer los profesionales en sus actividades particulares (Deontología) o, también, como ha sido puesto de manifiesto, de justificación de corporativismos que cuestionan las mismas reglas relacionadas con los comportamientos dentro de una profesión y, por tanto, los propios códigos deontológicos. Esta línea de exploración de la ética profesional como ética aplicada tiene tradición y ha sido objeto preferente de atención de los estudiosos de esta forma de racionalidad que se configura en torno a principios generales con ambiciones universalistas y pocas posibilidades de aterrizaje en situaciones concretas y reales. Los educadores sociales en España disponen de un código deontológico que de alguna manera define el "ethos" de la profesión de Educación Social. Nuestro objetivo es ofrecer una interpretación de la ética desde posiciones menos trascendentes y más inmanentes, lo que supone apostar por su construcción desde la práctica, desde las situaciones reales y relacionales vividas por los educadores sociales en las instituciones donde trabajan. Tratamos, así, de invertir el camino que transita de lo universal a lo particular, donde se aplican principios y supuestos, para recorrerlo en sentido inverso, reflexionando sobre las dimensiones éticas de la acción educativa en donde los educadores sociales, en relación, ponen en juego sus competencias y habilidades.

PALABRAS CLAVE: Educación Social, profesiones relacionales, profesionalismo, ética institucional, relación educativa, práctica ética, ética situacional o relacional e inmanente.

\begin{abstract}
Most of the ethical approaches related to professional activities, among which Social Education is included, have been put into practice from the field of the so called professional ethics which are usually thought from functionalist and idealizing approaches usually associated with a certain group of principles and imperatives formulated as a guide for orien-
\end{abstract}


tation for what professionals should do in their particular activities (deontological ethics) or, as it has been proven, with the justification of corporatisms which question the same rules related to the different behaviors existing in a profession and, therefore, their own deontological code. This line of research of professional ethics as applied ethics has a lot of history and has been subject of attention for researchers of this kind of rationality which have as starting point general principles with universalist ambitions and which has very few opportunities of generating specific and real situations. Social educators in Spain have deontological ethics that are somehow defining the "ethos" of the Social Education profession. Our goal is to offer an interpretation of the ethics from less transcendent points of view and to aim for its practical side, building it from real situations and from relationship created by the social educators in the institutions where they work. We try thus, to change the current way in which this goes from the universal to the specific, applying principles and assumptions to go through it in the opposite direction, thinking about the ethical dimension of educational action in which social educators, altogether and interacting, use their abilities and competencies.

KEY WORDS: Social education, relational professions, professionalism, institutional ethics, educational relationship, ethical practice, situational ethics or relational and immanent.

\section{Resumo}

A maioria das considerações éticas relacionadas com as actividades profissionais, incluindo a educação social é, houve chamadas de ética profissional, geralmente concebido a partir de abordagens funcionalista e idealizando e, muitas vezes associado a uma lista de princípios e imperativos formulado como um guia ou orientação do que fazer os profissionais em suas atividades particulares (de Ética), ou tam- bém, como foi mostrado, na justificação do corporativismo que desafiam as mesmas regras relativas à conduta dentro de uma profissão e portanto, seus próprios códigos de conduta. Esta linha de exploração da ética profissional, ética aplicada tem tradição e tem recebido atenção que preferencial dos estudiosos dessa forma de racionalidade que é configurado em torno geral ambições princípios universalistas e pouca chance de pouso em situações concretas e reais. Os educadores sociais em Espanha têm um código de ética que de alguma forma define o "ethos" da profissão de Educação Social. Nosso objetivo é oferecer uma interpretação da ética a partir de uma posição menos transcendente e mais imanente, que está apostando na sua construção a partir da prática, a partir de situações reais e relacionais vividos pelos assistentes sociais nas instituições onde trabalham. Tente, bem como, para reverter o caminho vai do universal ao particular, aplicando princípios e pressupostos, para atravessar em direção oposta, refletindo sobre as dimensões éticas da atividade educacional, onde educadores sociais, relacionados, em conjunto combinar suas habilidades e capacidades.

PALAVRAS-CHAVE: Educação Social, Profissões relacional, profissionalismo, ética institucional, relacionamento educacional, prática ética, ética situacional ou relacional e imanente.

\section{Introducción. La Educación Social: entre la Deontología y la Ética situacional}

Es frecuente en los estudios sobre profesionalización de las profesiones hacer referencia al papel de la ética en tal proceso. De hecho, se considera que una profesión con un cierto nivel de reconocimiento social y profesional ha logrado unas ciertas señas de identidad cuando ha sido capaz de formular el cuerpo de competencias específicas que le son necesarias para actuar en un área de intervención más o menos acotada, así como de 
elaborar un código de conducta que regula, en torno a normas, principios y reglas, todo aquello que tiene que ver con los comportamientos dentro de una profesión. Casi todas las profesiones establecidas, con una amplia tradición y visualización en el sistema económico, social y profesional, tienen sus propios códigos deontológicos, lo que con el tiempo ha dado lugar a un área de trabajo y formalización llamado Deontología. La Educación Social responde ampliamente a estos criterios alcanzando en pocos años un importante nivel de profesionalización, al menos entendida esta como un proceso en el que competencias, código, formación, capacidad asociativa... son requisitos fundamentales a la hora de profesionalizarse una profesión (Dubar y Tripier, 2005; Legault, 2003). Para algunos, entre los que nos encontramos, no se identifica Deontología con Ética; para otros esta asociación no tiene dudas. También, según el uso que se haga de ella, se opina con criterio, tendrá un código de conducta una base ética o no la tendrá.

"Es preciso distinguir atentamente la ética de la deontología. Una deontología consiste en reglas referentes a los comportamientos dentro de una profesión; pueden o deben tener, creo yo, una base ética, pero podrían ser o convertirse en una formulación de tipo jurídico, y es que hay deontologías que son simplemente formas de defensa y de autodefensa de las corporaciones individuales. Por lo tanto, la deontología no es necesariamente ética en su función y utilización. A menudo tiene una raíz ética que podría ser desmentida según el uso que se haga de ella" (Aimé: 2003,114).

En el caso de la Educación Social, el Código Deontológico tiene una base ética y es de suponer que debido a contingencias y particularidades, resumen del flujo de variables que la condicionan, no siempre consigue eludir las paradojas y contradicciones que generan la aplicación de principios generales y su dificultad para que se materialicen en la práctica.
Otra manera de pensar la ética ha sido la de acudir a los grandes principios formulados por Kant, Rousseau Rawls, Jonás y toda una serie de autores que han reflexionado sobre las distintas éticas o han contribuido a construirlas articulando sus argumentos en torno y a partir de tales principios más o menos generalistas: justicia, responsabilidad, honestidad, legalidad, autonomía, veracidad..., en suma, todos aquellos que han dado lugar a teorías éticas reconocidas en la historia de nuestra cultura (basada en derechos, en deberes, en las consecuencias...) (Suárez, 2001). Esta manera de abordar la ética nos la presenta, pues, como una forma de racionalidad antes que un simple método formal de principios que son aplicados mecánicamente a cualquier tema o problema humano que sea susceptible de tal tarea de "empaquetado": ello suele hacerse con frecuencia en el ámbito disciplinar, con frecuencia muy alegremente, promoviendo la imagen de que la ética es un territorio estático sobre el que no cabe nada que explorar (Burgess, 1989), un catálogo de recetas que muy bien puede aplicarse a cualquier objeto de estudio sin más. La ética va evolucionando y dinamizándose en sus distintas propuestas y formulaciones (Lipovetsky, 1999), cuestionando los hábitos etiquetadores de quienes la ven como un recurso estratégico que sirve para acallar voces discrepantes con las conductas de ciertos profesionales. La ética de la responsabilidad, de la justicia, de la veracidad, de la igualdad..., no sólo forman parte de nuestra cultura de un credo humanista que apela, en su interpretación más vital y generosa, a reconocer el derecho de las personas al bienestar, la salud, la educación y un tratamiento equitativo en su dinámica social..., sino que constituye el "alma del profesionalismo" (Freidson, 2001), ya que el profesionalismo es "un sistema de valores" (Evett, 2003), en donde buena parte de "los valores profesionales se erigen en obligaciones morales" (Dingwall, 1996) con las personas y sus intereses públicos, pero también con las instituciones en 
donde la intensidad y el impacto de las éticas profesionales, cuando se juegan en el escenario relacional de las organizaciones, acaban compensando la rigidez de ciertas normas burocráticas que limitan la posibilidad de relaciones más auténticas y "frescas" entre los que en ellas participan (Svensson, 2003). Los códigos deontológicos se sirven, con frecuencia, de estos principios y supuestos alentados por teorías éticas de gran peso cultural (Jonás y la responsabilidad social, Kant y el imperativo categórico, Ralws y su tematización sobre la justicia...); el problema es la utilización que se hace de ellos en la práctica profesional. Motivados por esta cuestión, estudiosos del campo de la Deontología y las Éticas fundamentales siguen explorando las repercusiones de la ética incrustada en el empeño humano hasta el punto de que los especialistas en esta línea de investigación piensan que si la ética no tiene un campo definido de estudio (a diferencia de la política, la economía y la educación que cuentan con una estructura y se orientan a sujetos y ámbitos determinados) es debido a que atraviesa todos ellos (Burgess, 1989); es decir, que la ética va tan vinculada al quehacer del hombre que toda su actividad es impregnada de carácter ético (Selsam, 1968).

Existe otra manera de pensar la ética en relación con la educación. En el sistema educativo, en los diferentes espacios educativos, esa ética de principios que comentábamos ha sido vinculada a toda una serie de temas y cuestiones que tienen que ver con la profesión de educador: ya sea a la hora de hablar de la formación, la intervención, la evaluación, el perfeccionamiento del profesorado, las relaciones de las instituciones educativas con los diferentes protagonistas de la práctica educativa..., la ética aparece vinculada, desde el exterior, a normas, patrones, principios que hacen referencia al ser y al hacer de la profesión. Pero podemos tomar otro recorrido adentrándonos en el interior de las actividades profesionales promovidas por los educadores en las que cabe discernir una dimensión ética. Esta inversión del camino que tradicionalmente ha recorrido la ética, yendo de la teoría (pensando en principios y supuestos con intenciones de aplicabilidad en la vida cotidiana: lo que reabre el debate sobre cómo conjugar lo general con la particularidad de la dinámica personal y social concreta de cada ser humano) a la práctica, supone tratar, por el contrario, de fundamentar la ética desde la praxis humana. Dado que las vías que van de lo universal a lo particular se han mostrado insuficientes para orientar éticamente las actividades inmanentes de los profesionales, se trataría ahora de construir la ética del educador social desde la base, la práctica profesional, de una profesión relacional como es la Educación Social, desde las situaciones que vive y en las que actúa "haciendo relación educativa”. Desde este punto de partida ya abordé el tema de la ética profesional relacionada con la Pedagogía Social, como campo de conocimiento que trata de dar razón de ser de una profesión como la Educación Social (Sáez Carreras, $2004 ; 2007$; 2005), teniendo la oportunidad de insistir en esta cuestión en el marco tanto de la profesionalización del campo como de la profesión (Sáez Carreras y García Molina, 2006) en los que, recurrentemente, tratamos de profundizar en varios de sus aspectos.

Esta colaboración está estructurada en dos partes, que se suman a esta introducción aclaratoria y a la bibliografía: en la primera, desde la lógica profesional y no disciplinar como suele hacerse frecuentemente (la externa a la profesión), llevamos a cabo, pensando en la Educación Social, un análisis sobre el papel atribuido a la ética en las profesiones, según los distintos enfoques sociológicos que la han estudiado, a fin de adquirir una comprensión amplia de los diversos planteamientos realizados sobre las actividades profesionales y sus roles éticos; la segunda trata de reflexionar, adentrándonos en una profesión relacional como es la Educación Social, sobre las di- 
mensiones éticas que comporta el trabajo educativo, lo ético vinculado a la relación educativa, aquella práctica educativa ética que se recrea en un espacio y una situación donde puede materializarse la profesionalización de los educadores sociales en sus vertientes concretas e inmanentes de relación profesional. El trabajo sólo esboza lo que potencialmente encierra.

\section{PRIMERA PARTE: LAS PROFESIONES Y LA ÉTICA. ALGUNOS ENFOQUES FUNDAMENTALES}

\section{1. El funcionalismo y la ética de imperativos}

No cabe duda de que en la historia de las profesiones, para relevar su importante papel o para cuestionarla, la ética aparece como un elemento fundamental desde los primeros estudios e iniciales definiciones que se dieron, durante la primera mitad del siglo XX, sobre las llamadas "ocupaciones" no manuales basadas en el conocimiento" (Abbott, 1988).

Las interpretaciones funcionalistas de Carr-Saunders y Wilson (1933), de Parsons (1954) o de Wilensky (1964), por sólo citar algunos de sus representantes más conocidos, defendieron que las profesiones ocupan un lugar eminente en la estructura de las sociedades hasta el punto de que forman parte constitutiva de la misma. Son un "fenómeno único" (Parsons, 1954, 1937) en la moderna civilización occidental y, como ya teorizara Durkheim (1985), aseguran la función ineluctable de dar cohesión social y promover el desarrollo moral en las sociedades industriales atravesadas por la anomia o el debilitamiento en los individuos de las normas y vínculos sociales necesarios para la solidaridad social. En tales sociedades, la división del trabajo cada vez más complejo y tecnificado, unido a una individualización progresiva y otras variables políticas y económicas (como la pobreza, los conflictos de clase, la falta de formación de la clase obrera...), demandaban la intervención de las corporaciones o grupos profesionales que constituían, a juicio del teórico francés, un poder moral único capaz de contener los egoísmos individuales, luchar contra los abusos de los poderosos y mantener o reconstruir la solidaridad común roída por la fragmentación y los diferentes efectos colaterales asociados a ella.

"Lo que ante todo vemos en el grupo profesional es un poder moral capaz de contener los egoísmos individuales, de mantener en el corazón de los trabajadores un sentimiento más vivo de su solidaridad común, de impedir aplicarse tan brutalmente la ley del más fuerte a las relaciones industriales y comerciales" (Durkheim: 1985, 12).

Las comunidades profesionales son, pues, en este planteamiento la base de las solidaridades orgánicas hechas de adhesión voluntaria, convicción personal y moral profesional constituyendo el paradigma moral de las sociedades que avanzan siendo las únicas capaces -ya que la escuela y la familia son dispositivos insuficientes y limitadosde restaurar esta "conciencia moral colectiva" necesaria para la convivencia social. Las profesiones ocupan, en fin, una posición intersticial en la estructura social mediando entre el Estado y los ciudadanos (Bertilsson, 1990) o articulándolas en la esfera del Mercado a fin de aminorar, o constituirse como alternativas, al mundo "egoísta" de los negocios. La educación moral propuesta por Durkheim tenía, en este sentido, un carácter fuertemente socializador ya que su misión consistía en tratar de que los ciudadanos interiorizaran un cuerpo de creencias y sentimientos comunes y se configuraran personas y colectivos morales por encima de las individuales. La noción de socialización iba, pues, muy vinculada a la de educación (Durkheim, 1976) y las dos, al mismo tiempo, a la de profesionalización ya que uno de los puntos fuertes de las profesiones, frente a las ocupaciones manuales y oficios, consistía en formar a las profesiones en el 
cuerpo de conocimientos relacionados con la profesión a la que trataban de acceder aquellos que se capacitan en ella (Parsons, 1954, 1979).

Como se ha confirmado, los primeros trabajos dedicados al estudio de las profesiones portaban esta concepción funcionalista enfatizando la necesidad de identificar los "rasgos" que constituían la peculiaridad, el sustrato esencial, el elemento común a todas las profesiones (Greenwood, 1957). Así, Wilensky (1964), haciendo referencia a los pasos que toda ocupación debe alcanzar para llegar a ser profesión, es decir, para profesionalizarse, teorizaba que debe adquirir o dotarse de una serie de atributos o rasgos como ser capaz de asociarse, lograr una protección legal del monopolio o del área de intervención de la profesión en su "jurisdicción laboral" (Abbot: 1988,16), dedicarse a ella con plenitud, promover campos de conocimiento especializado para formar a los profesionales de ayer y a los futuros, disponer de un cuerpo de competencias precisas y, desde luego, formular un código deontológico (Wilensky: 1964, 139).

Las ocupaciones que no tienen estos atributos no pueden ser consideradas profesiones y no lo serán hasta que los alcancen y se profesionalicen y, por tanto, no poseen la nobleza, libertad, independencia, la dignidad, la capacidad, la responsabilidad orientada altruísticamente hacia las demandas y necesidades de la comunidad. "Los valores del profesionalismo son los valores éticos por excelencia" (Legault: 2003, 39). Los teóricos y estudiosos de las profesiones vinculados al enfoque funcionalista apelan a una ética de imperativos, legalista y basada en los deberes (Suárez, 2001) para poder llevar a cabo esas funciones sociales que las simples ocupaciones, oficios o semiprofesiones (Etzione, 1969) no pueden cumplir. El profesionalismo precisa de la ética, recreada esta desde posiciones universalistas y kantianas.

"El estudio del profesionalismo nos sitúa en el dominio de lo deseable, de lo ideal en una relación profesional. Como todo fenómeno normativo, el profesionalismo propone valores y comportamientos ideales teniendo en cuenta el papel a ejercer. El profesionalismo no es una cuestión de hecho sino de ideal propuesto a las conductas profesionales y remite a la ética" (Legault: 2003, 41).

\section{2. El interaccionismo o el igualitarismo ético}

Los representantes del enfoque interaccionista (Hughes, Becker, Strauss, Glaser...) no comparten muchas de las ideas, argumentos y propuestas de la perspectiva funcionalista. No distinguen, por ejemplo, entre profesiones y ocupaciones porque para ellos todas las actividades humanas encierran en sí mismas esa dignidad que sociólogos, como Parsons o Wilensky le niegan a las ocupaciones. El oficio de un hombre es para ellos uno de los componentes más importantes de su identidad social, de sí mismo e incluso de su destino "en una existencia que no le es dada más que una vez" (Hughes, 1958). El igualitarismo cognitivo y ético fue una constante en los estudios interaccionistas.

Tampoco comparten esta visión metafísica y esencialista de las profesiones como si estas no emergieran en el tiempo y en el espacio, por lo tanto entienden que no existen las profesiones independientemente de los entornos en los que ellas están inmersas. De ahí que formularan, en colaboración con los teóricos críticos, una rigurosa denuncia a dos de las interpretaciones del enfoque funcionalista de las profesiones, presentadas por sus defensores como la avanzadilla del progreso y el reflejo de las tendencias racionalizadoras del conjunto de la sociedad cada vez más dominada por la ciencia, la tecnología y el capitalismo de Estado promotor del bienestar social.

En primer lugar, en lo que respecta al enfoque de "rasgos", que intentaba identificar con precisión lo que constituía la peculiaridad, el sustrato esencial, universal y común a 
todas las profesiones (Grenwood, 1957), el funcionalismo siempre fracasó por la imposibilidad de proponer las mismas características para todas ellas. No hay definición universal de profesión por mucho que las diferentes áreas de investigación en las Ciencias Sociales lo hayan intentado. Cuando se investigan las profesiones se muestra una serie de elementos, factores y variables diversas en cada uno de los casos estudiados (Wittz, 2003). Como se confirmó años más tarde, cuando Heidenheimer (1989) llevó a cabo un estudio detenido de diversas investigaciones sobre profesiones en EE.UU., Gran Bretaña y Alemania, las definiciones podían ser tantas como profesiones, por lo que es preciso optar por definiciones menos sustancialistas y trascendentales y más por nociones más concretas para poder estudiarlas en sus contextos congruentemente.

En lo que respecta al enfoque de "proceso", en segundo lugar, es cierto que las profesiones surgen, se hacen visibles profesionalizándose, se desarrollan o retroceden, cambiando y mutando a lo largo del tiempo y en espacios determinados. La idea de profesionalización, tratando de comprender desde una perspectiva dinámica el camino por el que una ocupación no manual se transforma en profesión, es revisada para comprobar que este proceso no es lineal, continuado, en fases predeterminadas (Vollmer y Mills, 1966), y no sólo incapaz de fijar esos atributos esenciales que creían comunes a toda profesión sino que también cuestiona el que tales exploraciones no hayan dado cuenta de las transformaciones producidas en una misma profesión, sujeta a contingencias, a dificultades y condicionamientos de diversa índole: la tensión profesionalización-desprofesionalización, asociada al par avance y promoción de la profesión versus retroceso o estancamiento de la misma, era una cuestión ya confirmada (Murphy, 1990): ¿qué es lo que hace que una actividad de trabajo pueda ser reconocida como profesión fuera de las descripciones y definiciones previas que se dan sobre ella?; ¿qué es lo que legitima que un grupo profesional obtenga para sus miembros las ventajas vinculadas a una profesión de las que no pueden disfrutar otras ocupaciones y oficios?; ¿por qué son más dignas las profesiones que las ocupaciones?; ¿por qué las personas que operan bajo el rótulo "profesional" son más morales que aquellas que no son profesionales? E insistiendo en esta dirección, ¿qué datos nos permiten confirmar que las acciones de los profesionales contribuyen a la cohesión social y al desarrollo moral de los grupos y las personas en comunidad y otras cuyas acciones se realizan bajo la cobertura de los oficios o las entregas del voluntariado, no logran alcanzar estas mismas metas?... Las preguntas se suceden y se abren a la investigación. El sistema conceptual de Parsons y de los funcionalistas en general no posibilita, a juicio de los interaccionistas, la utilización de instrumentos operativos para realizar investigaciones de naturaleza empírica.

"Es el resultado de una deducción lógica y de una contextualización de axiomas formales presentados bajo forma de combinación de 'variables'.

Este edificio teórico de argumentos y categorías no puede más que justificar conceptualmente el estatuto de las profesiones establecidas en la sociedad liberal (americana), puesto que adopta los postulados que traducen la ideología fundamentadora de estos grupos profesionales (médicos, abogados, ingenieros, enseñantes, distinguiéndolos de modo elitista de otros grupos ocupacionales). Los sociólogos parsonianos encuentran, globalmente, en estos grupos o en aquellos que les son próximos, 'estudiados desde el interior', a partir de la retórica de sus miembros, el mismo tipo ideal sin dejar manifestarse los rasgos específicos de cada uno. Contra esta manera de proceder actuarán los interaccionistas..." (Dubar y Tripier: 2005, 82). 


\section{3. La ola revisionista y crítica o la denuncia de la ética justificatoria}

En buena medida los argumentos apuntados por Hughes y los interaccionistas serán profundizados por Johnson (1972) y Larson (1977), y un grupo de teóricos de las profesiones cuando detectan el esfuerzo que hacen los profesionales, sobre todo de algunas profesiones, por dar una imagen estereotipada de ellos mismos poniendo en marcha toda una retórica de la disimulación: esa actitud que consiste en justificar el empleo que se ocupa, el oficio que se ejerce, del tal modo que pueda quedar de manifiesto la superioridad o el carácter excepcional de las profesiones (Hughes, 1992), reproduciendo la idea de que estas van vinculadas a actividades nobles y desinteresadas.

Para Johnson y Larson, esta retórica disimulatoria va más lejos, ya que no se trata sólo de denunciar las justificaciones morales que dan los funcionalistas para separar las profesiones de las ocupaciones y los oficios sino que se pretenden legitimar intereses económicos que pueden estar en abierta contradicción con la imagen de altruismo y desinterés, de moralidad y responsabilidad presentada por los grupos profesionales (neo) liberales. Detrás de las motivaciones vocacionales y morales están las políticas y las económicas. Este argumento resume la posición de los llamados representantes del "revisionismo" en la teoría de las profesiones: para ellos, los parsonianos hablan o se remiten a la ética cuando en realidad están haciendo ideología (Karz, 2007). Las prescripciones, principios o propuestas trascendentales no son otra cosa que un catálogo de recetas puesto en circulación para justificar y legitimar las ambiciones monopolizadoras de los grupos de poder. La "ola revisionista", por tanto, llevó a cabo durante un par de décadas, durante los años setenta y ochenta del siglo pasado, un análisis detenido de la literatura especializada sobre profesiones. Tales estudiosos, entre los que se encuentran autores ya clásicos en la historia de las profesiones como Johnson (1972), Larson (1977), Freidson (1978) y Abbott (1988), se sirvieron de referentes relevantes como Marx y Weber para sostener los trabajos que realizaron y publicaron. Aunque con divergencias y matizaciones en sus modos de abordar sus investigaciones -quizás el más distante sea Abbott, cargado de ánimo integrador de los diferentes discursos emitidos desde la lógica profesional, y el menos escorado Freidson, moviéndose entre ciertas propuestas interaccionistas y weberianas- todos ellos compartieron un buen número de argumentos en contra del enfoque funcionalista. Los que más se aproximaron en sus planteamientos fueron Johnson (1972) y Larson (1977). Con objetivos sintéticos ante todo, podríamos hacer algunas consideraciones que nos permitan entender la crítica a la ética, de alguna manera ya vista, a cierta ética utilizada como estrategia de poder corporativo utilizado por ciertos grupos económicos.

En primer lugar, hicieron una crítica a las profesiones por ser "monopolistas y elitistas", además de privilegiadoras, donde determinados actores colectivos, vinculados al Estado o al Mercado, buscan el control de sus respectivas áreas de trabajo a fin de que no entren en él miembros ajenos -o no deseados-a ellas. Por lo tanto, las profesiones no son un elemento "natural" ni constitutivo de la estructura social sino que son construcciones sociales (Mc Donald, 1995), que han surgido en un espacio, en una geografía, y también construcciones históricas" (Larson, 1977), emergentes en un tiempo en el que aparecen en el escenario, debido a determinados factores concretos y reales, procuran desarrollarse y profesionalizarse, transformándose según contextos y variables, a fin de promover el statu quo y las compensaciones económicas.

En segundo lugar, son una estrategia política, formas históricas de organizarse económicamente, funcionando con cierto nivel de "autonomía relativa" (Johnson, 1972) concedida por el Estado a través de la formación 
y las acreditaciones legitimadoras (Collins, 1989) para que se lleven a cabo ciertas actividades (relacionadas con la salud, la educación, el medio ambiente, la justicia, la vivienda...) reproductoras y necesarias para la dinámica social.

Desde estos puntos de partida, la ética es sólo una excusa, que forma parte de la ideología meritocrática, una vulgata de preceptos y recetas abstractas idealizantes que legitima el monopolio de la competencia, es decir, la capacidad legal para "cerrar" (la noción weberiana de "cierre social") el acceso de grupos y personas, que no poseen las disposiciones y capacidades exigidas, a determinadas "jurisdicciones laborales" (Abbott, 1988). Esta ideología de la competencia refinada y justificada como es la funcionalista constituye la forma más elaborada, a juicio de sus críticos, del profesionalismo contemporáneo. Un profesionalismo este que, en verdad, puede ser explicado por conceptos como el de poder, estructuras económicas, cierre social y cierre cultural, legitimidad política, intereses corporativos, monopolio organizado... en contraposición a los términos abstractos, utilizados por los funcionalistas, convertidos en atributos "a priori" de las profesiones, como actividades nobles y desinteresadas, vocación de servicio, entrega a la comunidad...

\section{4. El alma del profesionalismo y la ética institucional}

Con Freidson, sobre todo con su último texto, Professionallism. The Third Logic (2001), la visión pesimista de las profesiones formulada por los teóricos revisionistas, de algún modo atemperada por Abbott (1988), aunque este siguiera rechazando el punto de vista funcionalista en lo que respecta las justificaciones éticas, sufrirá, a su vez, aceradas críticas. La imagen o concepción del profesionalismo considerado como el proyecto y "soporte princi-

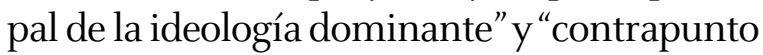
ideológico de la proletarización” (Larson: 1977,
239) es vuelta a replantear. Alejado de sus anteriores obras $(1978 ; 1986)$, Freidson se interpela y se aleja del espíritu que impregnó sus estudios anteriores disparando, también, contra sociólogos y teóricos críticos que no han sido capaces de ir a las cuestiones fundamentales propias del auténtico profesionalismo, pero también contra los ataques neoliberales que juzgan las corporaciones y organizaciones profesionales autónomas costosas e inútiles (Dubar y Tripier: 2005, 128129). Ir a las cuestiones fundamentales, con el fin de explorar las diferentes dimensiones del profesionalismo, significa preguntarse por cuestiones básicas como las siguientes: ¿Por qué el conjunto de los miembros de algunas profesiones invocan y utilizan este término en sus actividades cotidianas?; ¿qué es lo que significa ser un profesional?; ¿cómo construyen su profesionalidad?; ¿con atributos externos?; ¿ por certificados y credenciales?; ¿acaso la formación es el rasgo definitivo para lograr la profesionalidad?; ¿ la experiencia en ese terreno de intervención social para el que se supone estar preparado dominando competencias precisas?; ¿no habría que estudiar lo que hacen para saberlo?; ¿lo que hacen y cómo lo hacen?; ¿qué saberes pone, en realidad, en las situaciones laborales?; ¿qué estrategias utilizan para mantener su dominio en ese segmento laboral que cada profesión procura acotar...?

La tercera lógica es el profesionalismo y es una manera de pensar el mundo, como también lo son las otras dos, la lógica de mercado y la lógica burocrática o de las organizaciones formales. Cada una de ellas posee sus particulares lenguajes, teorías y conceptos. Las tres nos permiten describir y explicar los entornos en los que vivimos, las sociedades capitalistas avanzadas, y las tres mantienen una visión específica del trabajo en el siglo XXI.

"Mi intento es crear una lógica, una forma sistemática de pensar que pueda abarcar y ordenar la mayoría de los asuntos de los que ellos (Larson y Abbott) se ocupan, y demos- 
trar cómo esa lógica representa un tercer enfoque para comprender cómo el trabajo puede ser organizado y controlado" (Freidson: 2001, 6-7).

El profesionalismo es, por tanto, un conjunto de instituciones que permiten a los miembros de una ocupación ganarse la vida a la vez que controlan su propio trabajo, porque este se "ha especializado tanto que resulta inaccesible para los que carecen de la formación y la experiencia exigidas" (ibíd. pág. 17), de ahí la necesaria "división social del trabajo" a la que ya dedicaron buenas páginas tanto Marx como Durkheim (1985). Es en este punto donde se ubica el núcleo duro del profesionalismo: en "la exigencia de una especialización discrecional” (Freidson: 2001, 109). Especialización que sólo los especialistas, los profesionales, son los más capaces de abordar, de enfrentarse a un trabajo no racionalizado ni estandarizado (las burocracias) e, incluso, de evaluarlo y controlarlo adecuadamente. Ello explica la necesidad de una formación especializada y de una educación liberal capaz de preparar a los profesionales en la independencia y en la libertad, para actuar autónomamente en tareas de servicio a los demás porque "la ideología del profesionalismo reclama compromiso con un valor trascendente", con un objetivo de mayor alcance "encarnado en la defensa de valores como la justicia, la verdad, la salud, la belleza, la prosperidad..." (ibíd. pág. 123). Este es el profesionalismo típico ideal.

Ahora bien, el desarrollo y la promoción del profesionalismo no están exentos de contingencias que limitan su capacidad y su potencia. El Estado y el Mercado, las propias asociaciones profesionales, las instituciones y organizaciones... todos los actores están cargados de intereses y contradicciones, de ambivalencias y complejidades, condicionando la vida diaria profesional, los procesos donde se materializan las acciones de los profesionales (Burrage, Jaraush y Siegrist, 1990; Sáez Carreras, 2004, 2007; Sáez Carreras y García
Molina, 2006). Ello pone el profesionalismo en peligro. De hecho está siendo cuestionado frecuentemente por haber dejado que en su "alma", en el núcleo fundamental del profesionalismo, penetraran los valores propios de la lógica de mercado y la lógica burocrática. Acaso no hubo nunca una separación definitiva. ¿No está el modelo de empresa, salido del modelo liberal, reforzado por el neoliberalismo contemporáneo y la lógica de mercado, en camino de predominar sobre los otros modelos hasta el punto de absorberlos?; ¿qué queda de aquel profesionalismo parsoniano que el sociólogo americano oponía, por su nobleza, dignidad y responsabilidad, al mundo mercantil de los negocios orientados por el interés y el beneficio y no por el altruismo que se espera de los profesionales?; ¿no existe, visto con ojos contemporáneos, un antagonismo irreductible entre profesión y empresa?; ¿no está la lógica de mercado -con sus lenguajes, teorías y valores-impregnando todas las actividades profesionales?; ¿y qué decir de las invasiones burocráticas?; ¿qué tipo de relaciones han ido imponiendo (y radicalizándose) las burocracias modernas presentadas al principio del siglo XX como el modelo de racionalidad moderna que haría progresar las sociedades avanzadas?... El estatus del profesionalismo se encuentra noqueado. Las profesiones están ahí, existen; el profesionalismo, la filosofía y el espíritu que articuló, al menos en el discurso, su emergencia y existencia, se encuentra en declive (Freidson, 2001).

Así, algunos datos indicativos que muestran la complejidad de la situación, comienzan a dar la razón a sus críticos: pérdida de confianza pública en las profesiones (Pellegrino, 1991) y en algunos profesionales, presión para que se trabaje en torno a la resolución de problemas aplicados, mayor atención a problemas prácticos por parte de los teóricos de las ciencias sociales, entronización de capital privado en el dominio "desinteresado" de las profesiones, desprotección cuando no abandono de las profesiones por parte del Es- 
tado frente a las fuerzas del Mercado, pérdida de autonomía, proletarización en algunos casos profesionales con la consecuente desprofesionalización de la profesión en cuestión y de los profesionales vinculados a ella (Murphy, 1990)...El "ataque a la credibilidad de la ideología profesional", piensa Freidson, "ha sido un factor fundamental en el debilitamiento de las profesiones" así como en la frecuente defensa "de su voz moral independiente" (Freidson: 2001, 197), todo ello, unido a las clásicas críticas de credencialismo, elitismo, desigualdad, monopolización económica..., ha colocado al profesionalismo entre las cuerdas y de esta situación hay que salir "promoviendo una lógica persuasiva para defender lo que constituye su eje fundamental".

"Por tanto, el problema más importante para el futuro del profesionalismo no es ni económico ni estructural sino cultural e ideológico. El problema más importante es su alma" (Freidson: 2001, 213).

Ello remite a la ética. No basta con formular standars éticos que, por otra parte, contribuye a justificar la confianza del público tan importante para el profesionalismo. Para que este vuelva a imponerse de nuevo, es cierto, debe refinar, lo que supone elaborar con cuidado, sus códigos de ética y, además, tratar de fortalecer sus métodos para corregir y solucionar los problemas que surgen "cuando se violan los códigos" (Freidson: 2001, 216). Eso significa tener presente, por un lado, una ética institucional capaz de ocuparse no sólo del comportamiento de los profesionales sino también de "las circunstancias económicas, políticas, sociales e ideológicas que crean muchos de los problemas morales del trabajo" (Freidson: 2001, 216-217). Una ética que se ocupe de esclarecer la legitimidad moral de políticas e instituciones que están implicadas en el diseño, implementación y evaluación de las prácticas profesionales realizadas en organizaciones de diversa naturaleza. Una ética práctica, por otro, que dé cuenta de aquello que acontece en las relaciones profesionales, en las dinámicas laborales, a fin de rescatar, allí donde se hayan perdido, valores como la calidad y el trabajo bien hecho, la discrecionalidad y capacidad de autonomía para actuar con independencia, el compartir, contra toda competitividad, metas y medios en un trabajo conjunto orientado hacia el destinatario de la actividad... Freidson se interesa menos por esta ética práctica (Freidson: 2001, 220) o ética relacional, de la inmanencia que llamamos nosotros, pero es esta última la que va a articular los desarrollos de esta segunda parte porque es en ella, a nuestro juicio, donde podemos encontrar, además de otras propuestas complementarias sumadas a las de Freidson, el refortalecimiento del profesionalismo en todas las profesiones y, de modo particular, en la Educación Social. Un profesionalismo que pueda ser capaz de responder a esa interpelación permanente que surge del análisis del mundo contemporáneo: ¿es posible ser ético en sociedades dominadas por las burocracias y el mercado?; ¿de qué manera este predominio afecta a la Educación Social?; ¿ ‘a los educadores sociales trabajando en instituciones atravesadas por las racionalizaciones burocráticas estandarizadas y, en buena parte, gerencializadas por la lógica económica?

\section{SEGUNDA PARTE: DE LA PRÁCTICA PROFESIONAL A LA ÉTICA SITUACIONAL EN EDUCACIÓN SOCIAL}

\section{1. Práctica educativa y ética situacional}

Ya en su momento (Sáez Carreras, 2004; Sáez Carreras y García Molina, 2006) hicimos referencia a la ética en el marco de una propuesta de estudios de la profesión de Educación Social utilizando el concepto de profesionalización como eje articulador. Tratábamos de explorar las diferentes dimensiones de la citada profesión utilizando un modelo para estudiar la profesionalización que ha ido viviendo esta ocupación no manual en España, en particular, aun teniendo el refe- 
rente europeo siempre presente. Tal modelo se basaba en los actores, una propuesta que si bien apuntaban en su origen Burrage, Jaraush y Siegrist (1990), fue un estimulante poderoso para ahondar en él, como se ha puesto de manifiesto varias veces (Sáez Carreras, 2004, 2007; Sáez Carreras y García Molina, 2006). En este modelo la ética cumplía un papel fundamental para seguir pensando la profesión de Educación Social, y queremos seguir ahondando en algunas de las consideraciones que allí se apuntaron. Para ello, en este binomio tan fascinante como es el de ética y educación vamos a utilizar una estrategia, meramente analítica, como es la de plantear la siguiente división a fin de poder explicar con mayor nivel de comprensión la tarea que vamos a realizar:

\section{Ética y educación social}

1. Ética relacionada con la profesión. Deontología.

2. Ética relacionada con la práctica profesional. Justicia.

3. Ética relacionada con la acción educativa. Ética situacional o inmanente.

De estas tres asociaciones, la primera ha sido la más abordada con frecuencia (Wanjiru, 1995; Perrot, 2000; Fernández y Hortal, 1994), reconociendo algunos estudios particulares en el campo de la Educación Social vinculada a la Deontología como los de Pantoja y Rodríguez (2001) y Ronda (2003), por citar algunos de los más conocidos en esta área de investigación. Esta primera interpretación de la ética la separamos, tal y como hemos visto más arriba, de la segunda donde vinculamos la ética a la justicia. El argumento nos parece pertinente: una cuestión es la profesión, como construcción histórica y observada globalmente, donde toda una serie de factores y variables aparecen para explicarla (formación, autoorganización, competencias, políticas so- ciales, organizaciones vinculadas a la profesión...), y otra la práctica profesional, una de las muchas cuestiones particulares, de las dimensiones más elementales de toda profesión, ya que tiene que ver con las acciones de los profesionales y sus efectos en las personas y en los entornos donde se llevan a cabo. La tercera es la que más nos interesa en este momento y deseamos argumentarla sólidamente. La práctica profesional en Educación Social, como en toda profesión educativa, tiene que ver con el diseño y la elaboración de programas, con su ejecución o recreación según sea el modo aplicativo u orientativo que se lleve a cabo, con la evaluación de lo diseñado o realizado..., son varias las prácticas, en suma, que encuentran su cobertura en la noción de práctica profesional: también, como sabemos por estudios diversos (García Nadal, 2005; López Aróstegui, 1995), los educadores sociales también gestionan, archivan documentos, tratan de identificar las poblaciones a las que van a dirigirse, ... y realizan múltiples tareas y funciones que no son estrictamente educativas. Digamos para entendernos que entre las prácticas profesionales que ponen en juego el educador social, una de ellas es la educativa. De ahí que para distinguir esta práctica estrictamente educativa de las otras la llamaremos acción educativa o acto educativo: aquel que tiene lugar en la relación que se crea y se construye entre educadores y sus destinatarios. Esa relación, la llevada a cabo en ese acto de interacción, es la que podemos llamar relación educativa.

\section{2. La actividad humana como acción relacional}

¿Por qué esta estrategia metodológica? Existen razones sólidas para embarcarse en este proyecto investigador que sólo acaba de iniciarse. En primer lugar, porque la investigación en ética es amplísima a medida que ha ido creciendo el campo (Burgess, 1989); en segundo lugar, porque el discurso ético se ha centrado en la Deontología o en las distintas éticas apli- 
cadas y, escasamente, en la verdadera dinámica profesional. Se ha hablado casi siempre desde "fuera", desde el exterior de las profesiones y va siendo urgente que se construya el discurso desde "dentro", en el interior de las profesiones: se trata de seguir el camino inverso, como apuntamos en la introducción, un trayecto inductivo, constructivo, que contraste y complemente los discursos deductivos y aplicados, algunas veces trascendentalizados en una retórica abstracta y meramente especulativa, muy alejadas de la realidad, cuyas metas han sido interpretadas de modo muy diverso (Kultgen, 1988). Por lo tanto, se trata de trabajar y de explorar desde la propia lógica profesional y no desde otras lógicas más disciplinares (Sáez Carreras, 2004), aunque podamos servirnos de las muchas aportaciones que nos ofertan las ciencias sociales y naturales y, desde luego, todo ello con la finalidad de ir contribuyendo a la construcción del campo de conocimiento, la Pedagogía Social. En múltiples momentos, he insistido frecuentemente en que para enriquecer intelectualmente el campo hay que ir de la profesión, la Educación Social, estudiando sus prácticas y procesos, a la Pedagogía Social. Un recorrido, que ya hemos realizado varias veces (Sáez Carreras, 2004; Sáez Carreras y García Molina, 2006) y que, a nuestro juicio, merece la pena profundizar, aunque sólo sea por contrarrestar la ola de deduccionismo abstracto o de analogismo disciplinar que impera en este momento.

En consecuencia con esta demanda, es preciso recordar algunos de los supuestos sobre los que se apoya uno de los enfoques tan sólo aquí esbozado. Nos referimos a las teorías de la Escuela de Chicago, estudiosos de las profesiones, como son los interaccionistas. Para Hughes, como para otros representantes del citado enfoque, la actividad profesional debe ser estudiada como un proceso biográfico donde sean los propios profesionales, puesto que son los que están mejor situados, los que describan y analicen su trabajo. Trabajo, campo de tareas y funciones, que se ins- cribe en una trayectoria y en un ciclo vital que permite comprender por qué y cómo una persona hace lo que hace en su lugar de trabajo y en relación con otros (Hughes, 1958). Una actividad profesional que se sitúa en una dinámica temporal y que, como toda actividad humana, es relacional e interactiva.

"El doble punto de vista definido por los términos 'interacciones' y 'biografía' implica que todas las actividades de trabajo sean analizadas a la vez como procesos subjetivamente significantes y como relaciones dinámicas con los otros" (Dubar y Tripier: 2005, 89).

"Todo lo real es relacional", argumentaba Bordieu (1998). El argumento sociológico tiene un espléndido complemento en el ontológico: en la constitución de nuestra subjetividad "el nosotros" es previo al sujeto individual o al "yo" (Nancy, 2006). Las profesiones educativas, en tanto que son acciones dirigidas hacia destinatarios, se presentan como actividades de servicio y en ese sentido son "profesiones relacionales" (Demailly, 2008), en donde el nosotros, los yos y los otros, se encuentran inmersos en una realidad relacional. La ética relacional, pensando en la Educación Social como profesión pero sobre todo como práctica educativa, se plantea, al menos, dos grandes preguntas en relación con esta argumentación fundamentadora:

- ¿Qué es lo que acontece en la relación educativa donde se juega el nosotros, el encuentro entre un yo, un educador, y los destinatarios de sus acciones? Esta pregunta puede abordarse tratando de aproximarnos a algunos tipos de relación profesional que pueden darse en el territorio educativo.

- ¿Cuál es mi posición como educador en esa relación? La pregunta, muy foucaltiana, por cierto, remite a otras muchas como ¿qué tipo de educador quiero ser en esa relación?; ¿qué es lo que quiero hacer en la relación tratando de saber el tipo de educador que quiero ser y cómo construirme para ello...? 
Estas preguntas plantean la gran cuestión, casi siempre eludida y poco pensada, de la relación de un profesional consigo mismo al interior de un campo profesional. Poco pensada porque, normalmente, son variables externas, culturales, económicas y políticas las que han entronizado en los ciudadanos la imagen de este o aquel profesional, de cómo debe comportarse y qué es lo que debe hacer, sin apenas haber dado oportunidad, ni él personalmente haberla tomado, a que cada profesional, sea cual sea el campo de su acción, se piense a sí mismo como tal: pensarse a sí mismo, es verdad que dentro de un campo de saberes y poderes, para no ser sólo reflejo de posiciones dadas, apriorísticas, sino fruto del trabajo que el profesional de la Educación Social (o de cualquier otro profesional) realiza sobre sí mismo siendo consciente de que esa tarea incidirá en la calidad de la relación con los destinatarios de sus acciones.

Las dos preguntas formuladas remiten a la dimensión ética de las prácticas educativas, siempre relacionales, donde la pregunta permanente, ¿qué tipo de educador quiero ser?, no puede ser respondida por una ética de standards y normativas. Y no puede abordarse por este tipo de ética ya que en un punto de la respuesta se sabe que, por ser cada encuentro originario y por la subjetividad siempre particular de los que se encuentran... esta se singulariza, se personaliza. No hay subjetividades exactamente iguales. Tenía sentido, a nuestro juicio, la diferencia inicial que hicimos entre, por una parte, una ética de las profesiones, en sentido global, remitiendo a elementos normativos y códigos de conducta, y, por otra, una ética de la praxis educativa que soslaya o no se adentra en lógicas estandarizadas, ni en discursos generalistas, prescriptivos y universalizantes, tales como las éticas kantianas, en sus diferentes versiones, nos suelen presentar.

En lo que sigue, aun sabiendo de la profunda relación entre las dos preguntas, vamos a centrar nuestros desarrollos en la primera, postergando para otra oportunidad la pro- fundización de la segunda, tarea que ya iniciamos hace algunos años (Sáez Carreras y García Molina, 2006).

\section{3. La Educación Social como profesión relacional. Algunas tentativas de caracterización}

El adjetivo social nos da una visión inicial, una imagen global de qué tipo de profesión se trata, pero podemos aún insistir en este adjetivo si recorremos otras veredas. Así, la Educación Social forma parte, en otro tipo de clasificación, de las llamadas profesiones relacionales definidas, de modo global, como aquellas ocupaciones cuyas actividades fundamentales se centran en la relación. Podría decirse que ateniéndonos a la distinción humano-no humano, las profesiones relacionales son aquellas cuya meta, la finalidad de sus acciones, es "lo humano", frente a otras ocupaciones que se han ido configurándose orientadas por la naturaleza, la materia o los signos (p.ej. agricultores, constructores o matemáticos): las ocupaciones relacionales, pues, se definen esencialmente por aquello que tan gráficamente denominaba Dubet (2005) "profesiones del trabajo sobre el otro". No todas las profesiones relacionales pueden caracterizarse de forma similar pero, al menos, en el imaginario popular, funciona en el plano práctico una imagen de ellas en las que predomina el contacto, el calor, también los conflictos, desde luego los encuentros... y, por buscar contrastes, se oponen a las profesiones dominadas por la frialdad de la técnica, de la materia, la cifra o el papel (Demailly, 1991). Esta clasificación es, sin lugar a dudas, reduccionista ya que el componente relacional también ocupa un lugar importante en profesiones como las jurídicas, las dedicadas a la gestión o a la seguridad, la administración, las comerciales... Las relaciones profesionales en este tipo de ocupaciones tan "secas" se parecen poco a las "profesiones de servicio" en general y, particularmente, a las profesiones educativas como la Educación Social. Intentos de profundizar 
esta clasificación se encuentra en estudiosos franceses de los oficios. Es el caso de Lise Demailly quien en "Politiques de la relation" (2008) trata de construir modelos capaces de ubicar la dinámica de las profesiones en el espacio social. Varias tentativas podrían intentarse, a su juicio:

- Una primera tentativa podría formularse proponiendo una conceptualización de las profesiones planteándolas como un continuum que iría de las profesiones centradas sobre la persona y donde el trabajo de relación es el más importante de todas las funciones y tareas a realizar por los profesionales, a profesiones cuyas actividades de trabajo tienen un componente relacional más débil. La profesión como la Educación Social, cuya práctica profesional se centra fundamentalmente en la construcción de relaciones educativas, estaría en el nivel más alto del continuum. En cualquier caso, esta división también es problemática porque es difícil establecer fronteras objetivas, estables y firmes si nos atenemos a este criterio, entre unas profesiones y otras. Fronteras que no van a poder formularse por mucho que se quiera si se piensa en el carácter de las profesiones y en el conocimiento que las sustenta (Zouari, 2005).

- Una segunda tentativa trata de diferenciar las profesiones "del trabajo sobre otro" (dedicadas a actividades de educación, ayuda, consejo, cuidado, acompañamiento...), de las profesiones comerciales de servicio dedicadas a actividades de venta, ofertas de prestaciones, publicidad, viajes..., a fin de persuadir al otro del interés que tiene recurrir al servicio. No existe demasiada dificultad en situar a la Educación Social en esta clasificación, como una profesión en la que la ayuda, el consejo, el acompañamiento, el cuidado, la transmisión..., son funciones permanentes, casi consustanciales, de su despliegue profesional.
- Una tercera tentativa trataría de construir una tipología en función de varias polaridades. Una primera polaridad de actividades de relación concierne al objeto a transformar: en un polo, la transformación de la persona. Un comportamiento puntual (consumista) o un segmento del cuerpo (un órgano). Una segunda polaridad consideraría el uso de la relación como la herramienta central o no de la práctica. En un polo, la consistencia propia de la relación alimentaría un dato esencial de la definición de la práctica profesional (p.ej. la educación, la psicoterapia, el sacerdocio...); en el otro, la relación es un instrumento yuxtapuesto a otros medios de trabajo, siempre subordinado a fines externos.

Esta última clasificación clarifica la diversidad interna de los oficios de relación y también la diversidad global. Las profesiones relacionales presentan, como hemos visto, una especificidad con relación a las profesiones técnicas, tal y como argumentaron Dubet (2006), Gadrey (1994) y Demailly (1999). Es esta última investigadora, la que escribiendo sobre "los oficios relacionales de servicio público", mostró que la profesión de educador no podía ser identificada o considerada como otra, a causa de su componente ético. Su especificidad es evidente. En su último texto, Demailly (2008) hace referencia a una serie de consideraciones sobre la actividad de trabajo en las ocupaciones relacionales que permiten entender la especificidad de estas profesiones.

1. La importancia cuantitativa de los actos relacionales. Por definición la fuerte presencia de los actos relacionales en los procesos laborales caracteriza estas actividades.... Ningún trabajo humano está desprovisto de actos relacionales pero para ciertas profesiones se trata de una componente esencial que da una textura particular a la actividad de una profesión como la Educación Social. 
2. La implicación ético- política afecta a estas profesiones a nivel macrosociológico (vía políticas públicas) pero sobre todo a nivel microsociológico, a nivel cotidiano y situacional, puede ser pensada como una praxis. La dimensión ético-política es consustancial a los oficios de la relación (Sáez Carreras y Sánchez Martínez, 2005). Una práctica relacional convoca siempre, de intención o de hecho, una ética. En Educación Social, el componente ético es connotativo a la profesión.

3. Las dimensiones personales de los protagonistas de la actividad en las profesiones relacionales, afectan más fuertemente al contenido de la profesión que en el caso de las profesiones técnicas.

La Educación Social es una profesión relacional específica si nos atenemos a estas exigencias pero no olvidemos que, sobre todo, es una profesión pedagógica lo que permite afirmar que buena parte de sus prácticas profesionales, además de comportar relaciones de diverso tipo profesional, pueden adjetivarse de educativas $y$, por tanto, este tipo de práctica, en tanto que relacional, puede también expresarse con la noción de relación educativa.

\section{4. Relaciones profesionales, relaciones educativas}

El concepto de profesionalización, a juicio de Legault (2003) tiene que ver con la evolución de las profesiones y sus respectivas actividades. Estudiando este fenómeno social se pueden comprender mejor las características de la relación profesional siendo esta el punto de partida, la base, que nos permitirá comprender en qué consiste el profesionalismo y sus exigencias éticas. De este modo, la expresión relación profesional se convierte en la noción articuladora de cuatro de los conceptos base de la lógica profesional. Su esquema podría quedar de la siguiente manera:

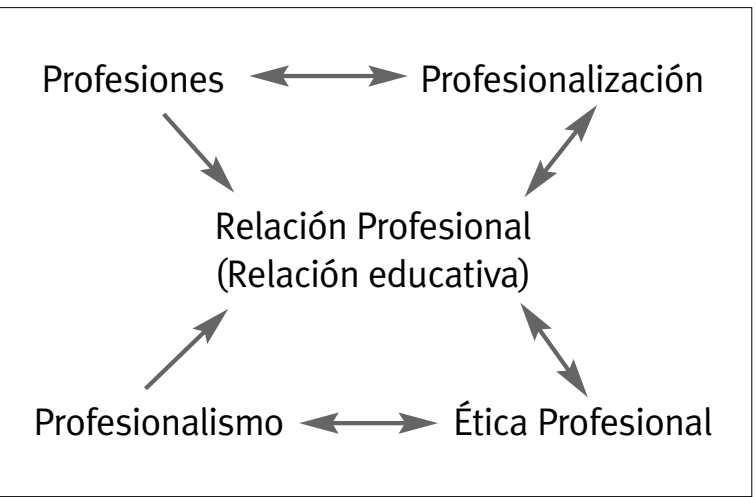

Cuadro de elaboración propia sobre los textos de Legault (2003).

La mayoría de estos conceptos han sido comentados a lo largo de estas páginas y sólo nos conduce el deseo de mostrar la potente articulación que existe entre ellos. Y en este momento, nos permite profundizar en los profundos vínculos entre los procesos de profesionalización de las profesiones y las prácticas profesionales como prácticas relacionales. Trato de decir que la profesionalización no es sólo una cuestión de empleo y de actividad económica sino también un movimiento que modifica las percepciones y las concepciones de la actividad social, ya que por las acciones de los profesionales en su entorno se resignifica la realidad social. La profesionalización de una tarea, de una actividad, de un trabajo, pasa por el reconocimiento en ese entorno social de la necesidad de ese servicio considerado un bien para la comunidad. Es ese reconocimiento el que demanda o provoca "la misión social" de las profesiones así como la calidad de la vida profesional (Legault: 2003, 12) y, también, el que nos permite comprender mejor "la naturaleza muy particular de la relación profesional” (Legault: 2003, 20). Ahora bien, una misma relación profesional, es pensada y vivida por los profesionales de manera diferente. Podríamos profundizar en esta cuestión de las relaciones profesionales haciendo algunas consideraciones al respecto.

1. La relación profesional debe ser "como una actividad esencialmente autónoma" (ibíd., 25). Muchos estudiosos han defen- 
dido este criterio como una variable profesionalizadora fundamental (Hughes, 1958; Parsons, 1979). Para algunos el único y exclusivo criterio por el que se identifica el nivel de profesionalización de una profesión o el de un profesional (Freidson, 1978, 2001). Los profesionales asalariados lo tienen difícil para serlo porque la relación profesional exige siempre autonomía en la acción. La autonomía tiene que ver con la libertad de decisión del profesional de la Educación Social que no puede ser limitada por las presiones de una institución. La realidad golpea con mucha frecuencia este deseo. ¿Autonomía?; ¿total?; ¿a qué nivel y grado?...

2. En la relación profesional de carácter pedagógico, el profesional no es un ejecutante. Esta relación es una relación de servicio. ¿Al servicio de quién trabaja el profesional? La respuesta a esta pregunta entra de lleno en el llamado "institucionalismo profesional". ¿Aceptan las instituciones las decisiones del profesional? Buena parte de los conflictos éticos actuales proceden de esta situación de los profesionales en las instituciones. La calidad de la relación viene determinada en buena medida por las decisiones autónomas que estén bien fundamentadas. Y es que la decisión de un profesional depende de su juicio profesional. "La naturaleza compleja del juicio profesional es una característica fundamental que ayuda a comprender la autonomía del profesional y su responsabilidad ante su cliente" (Legault: 2003, 26). Sin embargo, como sabemos (Sáez Carreras, 2004, 2007; Sáez Carreras y García Molina, 2006) los educadores sociales se encuentran presionados por varios frentes, institucionales y no institucionales, teniendo que tomar decisiones en contra de su percepción acerca del tema que se esté abordando.

3. La naturaleza particular de la relación profesional exige confianza. En las profe- siones articuladas sobre los bienes lo que se pone en juego es la calidad de la vida material; en las profesiones del cuidado, la calidad de la vida psíquica y física. Las decisiones profesionales no se pueden tomar alegremente y, en la relación, los clientes no pueden evaluar las decisiones del profesional por no poseer el conocimiento requerido. La relación en la que puede quedar atrapado el cliente es tan "peligrosa" como "dependiente". La relación profesional es, al fin y al cabo, una relación de poder y la llamada al "profesionalismo" es una manera que tienen las sociedades de limitar los abusos del profesional, ya que sin ello la pérdida de credibilidad en la profesión, y en los profesionales que pertenecen a ella, crece y con esta pérdida aparece el siempre permanente proceso amenazante de la desprofesionalización (Freidson, 2001).

\section{5. Tipos de relación profesional}

En Professionalisme et délibération éthique, Legault teoriza sobre diversos tipos o categorías de relaciones profesionales en función de cuatro variables, como son el grado de dependencia de la persona que consulta teniendo en cuenta la naturaleza del servicio en la sociedad, el nivel de conocimientos especializados requeridos, el grado de compromiso del profesional en el ejercicio de su profesión y el grado de autonomía de la persona que consulta $(2003,29)$.

Sin entrar a cuestionar la pertinencia de esta clasificación, y tomando este esquema como una oportunidad para ahondar en el tema de la relación profesional, nos detenemos con más detalle en los dos modelos categoriales que el autor denomina experto y cooperativo, todo ello pensando en la práctica profesional del educador social y, en particular, en la relación educativa.

La crítica al modelo paternalista (modelo que cuando es utilizado como referencia para 
Tabla 1: Categorías de relaciones profesionales

\begin{tabular}{|lcccc|}
\hline \begin{tabular}{|l} 
Categoría de relación \\
profesional
\end{tabular} & Grado de dependencia & Nivel de conocimientos & $\begin{array}{c}\text { Grado de compromiso } \\
\text { profesional }\end{array}$ & $\begin{array}{c}\text { Grado de autonomía } \\
\text { de las personas }\end{array}$ \\
\hline Adivino/Mago & Total & Esotéricos & Total & Nulo \\
\hline Paternalista & Casi total & Especializados & Casi total & Casi nulo \\
\hline Experto & Relativo a la competencia & Expertos & Relativo a la competencia & Casi total \\
\hline Consumidor & Nulo & Expertos pero discutibles & Nulo & Casi total \\
\hline Cooperativo & Relativa & Competencial & Compartido & Compartida \\
\hline \multicolumn{5}{|c}{} \\
\hline
\end{tabular}

Fuente: Legault $(2003,29)$.

la relación profesional supone que este se compromete a poner su saber especializado, de modo dominante, al servicio de la persona que acude a él) dió lugar, a juicio de Legault, a que fuera visualizándose en el escenario social y en el sistema profesional, una figura que venía emergiendo y construyéndose con la expansión de los sistemas industriales y el ascenso del capital. Nos referimos a la figura del experto.

"La relación de servicio deviene una relación de experto. Este modelo es diferente del modelo paternalista porque un experto es el que dice la 'verdad' sobre un tema dado. El modelo de experto viene a modificar la relación de dependencia entre el profesional y su cliente en la medida en que la noción de experto permite distinguir dos momentos de la relación profesional: la relación con el saber y la decisión de obrar" (Legault: 2003, 31-32).

El modelo de experto reserva el juicio profesional exclusivamente a la relación con el saber y como tal se concibe en un universo no interpersonal sino técnico. Se acude a un profesional porque se tiene un problema que puede resolverse de un modo técnico. Por lo tanto, este modelo limita la dependencia del sujeto que se educa a los resultados fomentado por el profesional y aunque la opinión del educador experto sea incontestable el destinatario de su acción es libre de seguirla o no. La autonomía del usuario es total, lo que no ocurre con los otros modelos. El compromiso del profesional acaba cuando propone la solución al pro- blema desde un plano técnico. El basamento del modelo de experto se sostiene sobre el supuesto de que existe una verdad suficientemente accesible para un caso dado y que todos los expertos en ese territorio de intervención deben estar de acuerdo y cuando no lo están surge el descrédito. La relación profesional en Educación Social no puede estar representada por el modelo técnico (Schön, 1992, 1998) en tanto que la deshumaniza. En la relación con el otro, con su cliente, el caso se plantea como un problema "técnico" que sólo tiene una solución técnica. La cuestión adquiere una dimensión más compleja cuando se trata de educar niños que educar adultos, como puede verse en las reflexiones siguientes.

El modelo de cooperación parece una respuesta a los límites del modelo de experto y de consumidor, al mismo tiempo que evita el retorno al paternalismo. En él "las responsabilidades son compartidas" y el profesional se cuida del otro "sin decidir por él". De ahí que "el modelo cooperativo humaniza la relación profesional poniendo el acento en la naturaleza del servicio dado a la persona" (Legault: 2003, 35), donde el saber práctico de un profesional es puesto "al servicio del proyecto de vida" de ella y en la que esta se compromete a clarificar con él la naturaleza de su proyecto vital. Este compromiso recíproco evita reducir la relación profesional al consumo de un servicio. Cuando en la relación profesional y en su ejercicio se tiende a favorecer el modelo de experto en las organizaciones e instituciones, 
la burocratización acaba impregnándolas. El modelo cooperativo, en una sociedad individualizada y burocratizada, apenas es tomado como referente en la relación profesional. En la relación educativa, como casi siempre, conviene matizar ya que dijimos que tiene una "textura" diferente dentro de la tipología de relaciones profesionales. Educar a la infancia no es lo mismo que hacerlo con adultos. La relación educativa en la primera es fundamentalmente ética; en la segunda ética y política. Con la infancia, los educadores tienen la obligación de incorporarles al mundo y para eso, llegado el caso, es preciso tomar decisiones por ellos. Con los adultos no es posible hacerlo porque la orientación y el destino de las acciones puestas en juego en la relación educativa le corresponde a ellos: son ellos los que deben decidir si desean educarse o no (Arendt, 2003). La relación educativa, en tanto que relación profesional, mantiene esa diferenciación frente a otras relaciones profesionales; también, desde el punto de vista pedagógico, esta relación insiste y profundiza en esa diferenciación cuando se trata de educar a la infancia o de trabajar educativamente con los adultos.

\subsection{Praxis profesional educativa e instancia ética situacional}

Si se trata de partir de la base de la práctica educativa, sabiendo que el recorrido es inverso al tradicional, ¿qué camino recorrer para llegar a elaborar propuestas éticas que, por inducción, se "desplieguen", del trabajo educativo?; más concretamente, ¿existen principios de tipo ético, no universalistas, que estén implicados en la relación educativa?; ¿tales principios tienen que ver con la construcción de esa praxis educativa? Hemos visto que no todas las prácticas profesionales eran las mismas como tampoco la relación educativa según sean sus protagonistas: ¿quiere ello decir que hay un modelo estándar de buena práctica profesional?; ¿de relación educativa atravesada por la excelencia permitiéndonos for- mular un tipo de ética acorde y constitutiva a tal práctica profesional?... No parece que la respuesta pueda ser afirmativa ya que, al menos analíticamente, acabaría por sustancializarse tanto la actividad profesional como sus dimensiones éticas. Supondría abocar en el esencialismo que se está cuestionando desde los inicios de este artículo. Una excelente práctica profesional, un solo tipo de relación educativa, soslayaría la contingencia y la particularidad de todo acontecer humano además de eliminar la subjetividad con la que opera cada individuo en esa relación promoviendo efectos singuralizantes en cada uno de los que se involucran en tales procesos (Wittorski, 2005). Sí que, en cambio, sin ningún ánimo determinista, finalístico o panmetodológico, se puede utilizar algún criterio, tratando de proseguir y favorecer ese camino inductivo al que nos estamos refiriendo a fin de seguir ahondando en una cuestión en la que están interpeladas las profesiones pedagógicas, en lo que nos ocupa la Educación Social, y sus respectivos procesos de profesionalización.

Ya en otro momento (Sáez Carreras y García Molina: 2006, 358-359) nos planteamos esta cuestión sin ningún tipo de reticencias al hacer referencia a los procesos de profesionalización. Justamente, debido al avance del estudio de las profesiones y sus respectivos procesos de profesionalización, a los conocimientos adquiridos y a la práctica ejercitada por los educadores, entre otros factores, se pueden formular algunas orientaciones que regulen la buena praxis, definidas no sólo por la racionalidad eficaz sino también por comportamientos entendidos cómo éticamente aceptables en el trabajo educativo. Se pueden enumerar, así, algunos criterios ampliamente aceptados como guías de la "buena praxis profesional" que pueden desarrollar los educadores sociales:

\section{Respeto por el carácter único de cada in-} dividuo es un principio fundamental que insta a los educadores a no actuar con visiones recetarias de la práctica educativa. 
2. Aceptación de la diversidad, significante con significados mucho más amplios que la tolerancia -considerada no sólo un principio sino también una exigencia continua- en el "reconocimiento al otro".

\section{El reconocimiento de la diversidad de} contextos y ambientes culturales en los que los educadores son llamados a actuar, nos confirma que las experiencias no son transferibles sin más, como fotocopias, a otros posibles ámbitos.

4. Reconocimiento del carácter singular y único de cada relación educativa.

5. Necesidad de considerar al usuario/ cliente como una persona global. No debiera educarse bajo el supuesto de que el sujeto carece de algo, tiene un falta o algún aspecto no funciona correctamente El educador social se dirige a la persona en su complejidad, con sus necesidades, sus deseos e intereses, sus potencialidades, sus capacidades y su límites. Ni unos ni otros deben extraerse a priori, porque ellos son los que aparecen en el transcurso de la relación educativa, posibilitándola y/o impidiéndola.

6. La necesidad de estar atentos a una organización y gestión de los servicios y de las instituciones que no contribuya a la marginación y a la exclusión. A veces, es la misma agencia que ha de trabajar para la inclusión la que, quizás de forma poco consciente, produce prácticas y efectos marginadores. Algunas tipologías de servicios sanitarios, sociales y socioeducativos contribuyen, con sus saberes, a producir categorías reificadoras tales como "toxicómano", "familia multiproblemática", "población diana", que no dicen nada de la particularidad de cada sujeto, pero presuponen mucho acerca de lo que cabe hacer con, o esperar de, ellos.

7. Intencionalidad educativa que se traduce en proyectos abiertos a lo indeterminable. En las prácticas educativas se encuentran siempre dos elementos ineludibles: la complejidad y la incertidumbre. El educador es responsable de lanzar un puente hacia "posibles futuros del otro", pero no puede ignorar que es "el otro" quien decidirá sobre lo apropiado de la apuesta. La práctica educativa no puede pre-planificarse de manera absoluta, ni encasillarse en guiones preestablecidos.

8. La educación necesita tiempo y mucho más que el aprendizaje. Seguramente Rousseau tenía razón en este punto: en educación, más que de ganar tiempo, se trata de perderlo.

Ante la incertidumbre, la complejidad, la precariedad y las contradicciones de su trabajo, los educadores sociales suelen encontrarse ante dilemas a los que los criterios y las normas escritas no siempre pueden dar respuesta. Estos dilemas y retos convocan a los educadores sociales a dar una dimensión política y ética a su trabajo. Una respuesta ética que no quiere alimentarse de imperativos formales o de éticas universales sino construirse partiendo de la acción educativa, de la buena praxis educativa que conlleva implícitamente ética. En torno a la praxis educativa ética, escribe O. Aimé:

“ ¿Hay o no una dimensión ética en la práctica educativa? Si la hay ¿de qué naturaleza es?; ¿debemos explicitarla o quizás la debemos tomar como algo evidente e indiscutible? La tendencia cultural del individualismo de hoy nos lleva a decir que, sobre estas cosas, cada uno responde sólo ante sí mismo; entonces, llegados a este punto, se trata de entender la dimensión ética. Subrayo que es impalpable, es necesaria pero impalpable..., porque siendo el código deontológico más palpable no podrá nunca sustituir instancia ética alguna" (2003, 1)

Todas estas orientaciones, esta guía de actuación de los educadores sociales, tendrá la posibilidad de materializarse en un lugar inmanente, concreto y situacional, como es el espacio donde se trabaja. Los dispositivos 
que facilitan el autoanálisis de las prácticas profesionales, además de revelarse como un instrumento de formación excelente, se convierten en medios potentes de transformación de la experiencia (Clot y Faita: 2001). Una experiencia que va vinculada a la transformación de un sujeto en el contexto de una situación de una actividad realizada. El encuentro relacional donde tiene lugar el acontecimiento, no es otra cosa que la actualización de una de las actividades realizables en las situaciones cotidianas. Esto es lo real de la actividad: el conjunto de lo que se ha hecho, también de lo que no se hace y de lo que se desea hacer..., todas estas acciones deben ser contempladas en el análisis como Clot y Faita proponen a través de su método "autoconfrontación cruzada”. El análisis de los trabajos realizados, diversos y variados, permiten captar las diversas posibilidades y vías de profesionalización de la Educación Social pero, sobre todo, comprender la transformación de las personas en la acción. En la relación educativa tiene lugar la acción de determinados sujetos implicados en una práctica profesional. La noción de acción nos interpela y observamos, a medida que profundizamos, que son muchos los autores que han teorizado sobre ella: impulso, resultado, sentido activo y pasivo, conducta, "lo que hacen los hombres y lo hacen por ellos mismos"..., la acción siempre se ubica en un "cuadro de experiencia" que estructura la manera en la que percibimos la situación y el modo de obrar (Goffman, 1974). La acción es siempre acción situada. Una acción cuyo dominio es el de la contingencia y de la singularidad, de ahí que toda acción educativa sea particular y sus efectos sean siempre personales y subjetivantes. Es, pues, una configuración singular que articula estrechamente al actor y la situación que vive y experiencia (Wittorski, 2007). Ella es concebida como el producto contingente y momentáneo de intercambio entre personas en y con un contexto. La acción es real y lo real es relacional. La acción relacional como relación edu- cativa es, también, relación ética. La acción educativa es, en suma, una acción ética. Es desde esta ética situacional, desde la que, a nuestro juicio puede construirse una ética más sólida, inmanente, y menos trascendental e imperativa. Un modo, al fin y al cabo, de reconstruir el profesionalismo que en los últimos tiempos se encuentra vapuleado. Una línea de investigación innovadora que puede fermentar los diversos campos profesionales y sus diferentes actividades así como los respectivos campos disciplinares que tratan de dar razón de ellos.

\section{Referencias bibliográficas}

Abbott, A. (1988): The System of Professions. An Essay on the Division of Expert Labour. Chicago: University of Chicago Press.

Aimé, O. (2003): “Una prospectiva ética per il XXI secolo: il contributo di Paul Ricoeur", en Chiarle, R.; Pidello, M.; Ronda, L. (coords.): La responsabilitá dell'educatore professionale. Roma: Carrocci Editore, pp. 75-92.

Aimé, O (2003): "Fondare l'ética della prassi educativa", en Chiarle, R.; Pidello, M.; Ronda, L. (coords.): La responsabilitá dell'educatore professionale. Roma: Carrocci Editore, pp. 113-127.

Arendt, H. (2003): Entre el pasado y el futuro. Barcelona: Península.

Bertilsson, M. (1990): "The Welfare State, the Professions and Citizens", en Torstendahl, R.; Burrage, M. (cords.): The Formations of Professions. Londres: Sage, pp. 114-133.

Bordieu, P. (1998): La distinción. Madrid: Taurus. Burgess, R. G. (1989): The Ethics of Educational Research. Nueva York: The Falmer Press.

Burrage, M.; Jaraush, K.; Siegrist, H. (1990): "An actor-base framework for the study of professions", en Burrage, M. y Torsthendahl, R. (cords.): The Formations of Professions. London: Sage, pp. 203-240.

Carr- Saunders, A. y Wilson, P. (1933): The professions. Oxford: Clarendon Press.

Clot, Y. y Faita, D. (2001): "Entretiens en auto confrontation croisée". Education Permanente, 146, pp. $17-25$. 
Collins, R. (1989): La sociedad credencialista. Madrid: Akal.

Demailly, L. (1991) : Le collége: crise, mythes et métiers. Lille: Presses Universitaires de Lille.

Demailly, L. (1999) : "Les métiers relationnels de service public: approche gestionnaire/approche politique". Lien Social et Politique, avril, pp. 17-24.

Demailly, L. (2008) : Politques de la relation. Villaneuve d'Ascqu : Presses Universitaires du Septentrion.

Dingwall, R. (1996): "Professions and social order in a global society". Plenary presentation at ISA working group 02 Conference. Nottingham, 1113 de September.

Dubar, C. y Tripier, P. (2005): Sociologie des professions. París : Armand Colin.

Dubet, F. (2005) : Injustices. L'expérience des inégalités au travail. París: Seuil.

Dubet, F. (2006): El declive de las instituciones. Barcelona: Gedisa.

Durkheim, E. (1976): Educación como socialización. Salamanca: Sigueme.

Durkheim, E. (1985): La división del trabajo social. Barcelona: Planeta-Agostini (2 vols.).

Etzione, A. (coord..) (1969): The Semi-Professions and their Organization. Nueva York: Free Press.

Evett, J. (2003): "Sociología de los grupos profesionales : historia, conceptos y teorías", en Sánchez, M.; Sáez, J.; Svensson, L. (coords.): Sociología de las profesiones. Pasado, presente y futuro. Murcia: Diego Marín Editor, pp. 29-51.

Fairbairn, G. ( 2003): "Ethics: a central focus in the professional practice and education of the social professions?". Journal of Social Education, 3, pp.55-67.

Fernández, I. L.; Hortal, A. (1994): Ética de las profesiones. Madrid: Universidad Pontificia de Comillas.

Foucault, M. (2003): El yo minimalista y otras conversaciones. Buenos Aires: La Piqueta.

Freidson, E. (1978): La profesión médica. Barcelona: Península.

Freidson, E. (2001): Professionalism. The Third Logic. Cambridge: Polity Press.

Gadrey, (1994) : "La modernisation des services professionnels”. Revue Française de Sociologie, 35, pp. 163-195.
García Molina, J. (2003): Dar (la) palabra. Deseo, don y ética en educación social. Barcelona: Gedisa.

García Nadal, A. (2005): La profesionalización del educador social: entre la formación y la experiencia profesional. Murcia: Universidad de Murcia. Tesis Inédita.

Greewood, E. (1957): "The Attributes of a Profession". Social Work, 2, pp. 44-55.

Goffman. E. (1974): Les cadres de l'expérience. París: Minuit.

Heidenheimer, A. (1989): "Professional Knowledge and state policy in comparative historical perspective: laws and medicine in Britain, Germany and the United States". International Social Science Journal, 122, pp. 529-553.

Hughes, E. (1958): Men and their work. Glencoe: The Free Press.

Hughes, E. (1992) : Le regard sociologique. Paris: Edit de L'EHES (compilación de textos debida a J. M. Chapouli).

Johnson, T. (1972): Professions and Power. Londres: Mc Millan.

Jonas, H. (1995): El principio de responsabilidad. Ensayo de una ética para la civilización tecnológica. Barcelona: Herder.

Kärz, S. (2007): Problematizar el trabajo social: definición, figuras, clínica. Barcelona: Gedisa.

Kultgen, J. (1988): Ethics and professionalism. Philadelphia: University of Pensylvania Press.

Larson, M.S. (1977): The Rise of Professionalim: A Sociological Analysis. Berkeley: University of California Press.

Legault, G. (2003) : Professionalisme et délibération éthique. Québec: Présses de l'Université du Québec.

Lipovetsky, G. (1999): El crepúsculo del deber. Barcelona: Anagrama.

López Aróstegui, R. (1995): El perfil profesional del educador social y la Educación Social en Euskadi. Vitoria: Gobierno Vasco.

Mc Donald, K. (1995): The sociology of professions. Londres: Sage.

Murphy, R. (1990): "Proletarization or Bureaucratization: The Fall of the professional?", en Torstendhal, R.; Burrage,M. (coords.): "The Formation of Professions: Knowledge, State and Strategy. Beverly Hills, California: Sage, pp. 71-96. 
Nancy, J. L. (2006): Ser singular/plural. Madrid: Arena Edit.

Pantoja, L. y Rodríguez, I. (2001): "Un esbozo de código deontológico para educadores sociales: proceso de elaboración y situación actual". Educación Social, 17, pp. 88-110.

Parsons, T. (1937): "Remarks on Education and the professions". International Journal of Ethics, 47, pp. 365-370.

Parsons, T. (1954): "The Professions and Social Structure", en Parsons, T. (coord.): Essays in Sociological Theory. Nueva York: Free Press.

Parson, T. (1979): "Profesiones liberales", en Enciclopedia Internacional de las Ciencias Sociales. Madrid: Aguilar, pp. 538-547.

Pellegrino, E. D. y otros (1991): Ethics, Trust, and the Professions. Washington: Georgetown University Press.

Perrot, E. (2000): Ética profesional. El discernimiento en la toma de decisiones. Bilbao: Edit. Mensajero.

Rawls, J. (1979): Teoría de la justicia. México: F.C.E. Ricoeur, P. (1996): Sí mismo como otro. Madrid: Siglo XXI.

Ronda, L. (2003): "Alla ricerca del codice deontológico dell éducatore professionale", en Chiarle, R.; Pidello, M.; Ronda, L. (coords.): La responsabilitá dell'educatore professionale. Roma: Carrocci Editore, pp. 193- 208.

Sáez Carreras, J. (2004): Proyecto docente e investigador de Pedagogía Social. Murcia. Documento inédito parcialmente.

Sáez Carreras, J. (2005): "La profesionalización de los educadores sociales". Revista de Educación, 336, pp. 129-139.

Sáez Carreras, J. (2007): Pedagogía Social y Educación Social. Historia, profesión y competencia. Madrid: Pearson.

Sáez Carreras, J.; Sánchez Martínez, M. (2005): "Professionalization of Social Education in the Welfare Mix. Highlights from the Spanish Experience", en Divay, S. (coord.): Welfare and Caring Professions. Paris: L'Harmattan. También en Knowledge, Work and Society, vol. 3 (2), pp. 81-101.

Sáez Carreras, J.; Sánchez Martínez, M. (2006): "Trust and Professionalism in Social Professions:
The Case of Social Education", Current Sociology, vol. 54 (2), pp. 595-607.

Sáez Carreras, J.; García Molina, J. (2006): Pedagogía Social. Pensar la Educación Social como profesión. Madrid: Alianza.

Schön, D. (1992): La formación de los profesionales reflexivos. Barcelona: Paidós.

Schön, D. (1998): El profesional reflexivo. Barcelona: Paidós.

Selsam, H. (1968): Etica y progreso. Mexico: Grijalbo.

Suárez, I. C. (2001): Principios de Ética Profesional. Madrid: Edit. Técnos.

Sullivan, W. M. (1995): Work and integrity: the crisis and promise of professionalism in America. New York: Harper Collins.

Svensson, L. (2003): "Introducción a la Sociología de las profesiones”, en Sáez, J.; Sánchez, M.; Svensson, L. (coords.): Sociología de las profesiones. Pasado, presente y futuro. Murcia: Diego Marin Editor, pp. $13-28$.

Torralba, F. (2001): "La llamada del otro vulnerable. Hacia una fundamentación de las éticas profesionales". Educación Social, 17, pp. 27-42.

Vilar, J. (2001): "La ética en la práctica cotidiana de las profesiones sociales". Educación Social, 17, pp. 10-26.

Vollmer, H. M.; Mills, D. L. (1966): Professionalization. Nueva Jersey: Englewood Cliffs.

Wanjiru, G. (1995): La ética de la profesión docente. Estudio introductorio a la deontología de la educación. Pamplona: Eunsa.

Wilensky, H. (1964): "The professionalization of Everyone?". American Journal of Sociology, 2, pp. 137-158.

Wittorski, R. (coord.) (2005): Travail, formation et professionalisation. Paris: L'Harmattan.

Wittorski, R. (2007): Professionnalisation et développment professionnel. París: L'Harmattan.

Wittz, A. (2003): "Patriarcado y profesiones", en Sáez, J.; Sánchez, M.; Svensson, L. (coords.): Sociología de las profesiones. Pasado, presente y futuro. Murcia: Diego Marín Editor, pp. 93-121.

Zouari, Y. (2005): "Pour un questionnement épistémologique des savoirs d'action", en Astofi, J.P. 
(coord.) : Savoirs en action et acteurs de la formation. Ruán: Pur, pp. 63-72.

DIRECCIÓN DE LOS AUTORES:

Margarita Campillo Díaz y Juan Sáez Carreras. Facultad de Educación. Universidad de Murcia.

Correo electrónico:

marga@um.es y juansaez@um.es
Fecha de recepción del artículo: 04.IV.2011

Fecha de revisión del artículo: 04.IV2011

Fecha de aceptación del artículo: 15.VI.2011

\section{COMO CITAR ESTE ARTÍCULO:}

Sáez Carreras, J. (2011). "Por una ética situacional en Educación Social”, en Pedagogía Social. Revista Interuniversitaria, 19, pp. 13-36. 